\title{
Fstudio y documentación de los Capuchinos en Melilla y Vélez de la Gomera
}

\author{
José Luis Blasco López
}

Asociación de Estudios Melillenses

Nos encontramos en el año 1209 cuando Francisco de Asís envía por el mundo a sus religiosos para que empiecen a predicar el Evangelio de Jesucristo. Entonces tan sólo contaba con ocho compañeros y aún el Papa no había aprobado lo que más tarde sería la Orden Franciscana.

Hacia el año 1221 llegaban los cinco primeros frailes franciscanos a lo que hoy en día conocemos por Marruecos. Estos a causa de su martirio llegarían a ser conocidos como los Mártires de Marruecos: Berardo, Pedro, Acursio, Adyuto y Otón.

Años después les llegaría el turno del martirio a los llamados Mártires de Ceuta: Daniel, Samuel, Dónulo, Hugolino, Nicolás y Angel, amén de una interminable lista de frailes que sufrieron el destierro, la esclavitud, persecuciones y calamidades.

Con la conquista para España por la Casa Ducal de Medina Sidonia, la Giudad de Melilla dependía del Arzobispado de Sevilla y del Obispado de Cádiz para controlar estos el Pan de las Tercias con destino a las cuatrocientas veintiuna personas que el duque tenía en esta Ciudad. Del mismo modo el obispo de Badajoz, don Juan Fonseca, controlaba el precio del trigo que se trasladaba a Melilla. "así del flete como del acarreto para que aquello se abaje". 
Su santidad el papa Pío V expedía una Bula fechada en Roma el 5 de julio de 1566 por la que incorporaba la Iglesia de Melilla al Obispado de Málaga, alcanzando los religiosos y sacerdotes el rango de "Quassi propios rectores".

A lo largo de todo el siglo XVI los religiosos gozaron del privilegio de "absolver a todos, a culpa y pena, antes de entrar en combate", en virtud de pertenecer a la Casa de Niebla.

Llegamos al año 1648 en que el Rey escribe a su embajador en Roma para que consiguiese del Papa la Bula pertinente para hacer posible la Fundación de los Capuchinos en Melilla y Vélez de la Gomera. Para ello hizo valer todo su poder indicando asimismo el modo en que vivían en el Congo, Guinea y Puerto de San Miguel de la Mahámora. Recordó a su embajador que el permiso para la Misión de Africa estaba para caducar y era necesario renovarlo.

A pesar del interés Real no fue posible esta fundación por cuanto el Provincial de los Capuchinos contestaba a don Blasco de Loyola, que comprendía la voluntad real, pero que no tenía religiosos disponibles para enviar a estos Presidios.

Así que Felipe IV recibe esta contestación, se muestra tajante y ordena el envío en los siguientes términos:

Reverendo y devoto P. Fray Leandro de Antequera, Provincial de los Capuchinos de Andalucia: e visto lo que respondeis a D. Blasco de Loyola a lo que de mi orden os escribió cerca de los religiosos que han de pasar a las Plazas de Melilla y Peñón, y aunque representais la dificultad que se os ofrece en la ejecución, por haber muy poco número en esa provincia, y otras razones que poneis en consideración, todavía por ser preciso al servicio de nuestro Señor y mío se pongan en aquéllas Plazas los que tengo resuelto, porque no hay en ellas quien administre los sacramentos, os vuelvo a mandar de nuevo que luego que recibais este despacho nombreis tres sacardotes para la Vicaría y Curato de Melilla y un Religioso Lego que les asista, $y$ otros dos sacerdotes para la Vicaría $y$ Curato del Peñón de Vélez, y un Religioso Lego que les asista procurando encaminar sea nombrado Fray Alejandro de Gra- 
nada y los demás que les pareciere son a apropósito para ellos, $y$ si esto no fuere posible eligireis los que juzgareis ser más conveniente para aquellos presidios: Enviareis los nom- . bres señalando los que han de ser Vicarios y Curas, y para como tengo mandado se les de disposición para que puedan confesar, y el Obispo de Málaga los nombramientos de Vicarios y Curas, y también se den los demás despachos que han de llevar, $y$ tendreis entendido que estos religiosos han de estar sometidos a vuestra obediencia, $y$ del que os sucediere en vuestro Oficio, y que muriendo alguno a habiendo causa para sacarlo de dichos presidios, Vos o los que os sucedieren en el cargo lo han de poder hacer enviando otro en su lugar de forma que el número esté siempre entero. Dado en Madrid a veinte de agosto de mil seiscientos sesenta.- Yo el rey.

Hemos creído conveniente resaltar que cualquier hecho histórico o referencia documental sobre la iglesia y convento de Capuchinos habrá de ir siempre unido a los nombres de su majestad el rey don Felipe IV "Fundador y patrono en lo temporal de esta santa iglesia" (1), al Obispado de Málaga, su auténtico propietario desde el año 1682 tal y como demostrara el presbítero don Juan de Lara Ramos (2) en escrito de 3 de diciembre de 1866, siendo estimado por el señor Asesor en su dictamen de 22 de diciembre de dicho año, y a la Orden de Frailes Menores Capuchinos de la provincia de Andalucía (3) que la tomó a su cargo por Real Cédula de 26 de octubre de 1660 expedida en el Real Sitio de San Lorenzo de El Escorial.

El obispo de Málaga don Antonio de Piña y Hermosa ratificaba con fecha de 27 de noviembre de 1660 en la ciudad de Antequera (4) los nombramientos de vicarios y curas para Melilla y Vélez de la Gomera, decretando así mismo el Santo Oficio (5) a favor de fray Basilio de Antequera (6) y fray José de Granada (7) los nombramientos de Comisarios del Santo Oficio de la Inquisición (8) en la ciudad de Granada con fecha 5 de noviembre de 1660.

Perfectamente documentados, llegan los Capuchinos a Melilla y Vélez de la Gomera, tomando posesión primero de la Real y Pontificia iglesia de la Concepción (9) el día 15 de mayo de 1661, y unos días des- 
pués, de la iglesia de Santiago el Real (10) el 29 de enero del mismo año, tal y como había ordenado el Rey al Sargento Mayor don Francisco de Solís, Alcayde de la Fuerza del Peñón por medio de la Real Cédula de 26 de octubre de 1660 (11).

Entre otras muchas cosas decía don Felipe IV al Alcayde de Vélez: "Os mando que luego que lleguen les señaleis y pongais en su recogimiento incorporado con la Iglesia y no en otra parte" (12).

Cuando llevaban pocos días instalados los religiosos en sus respectivas iglesias, expedía el Monarca una nueva Real Cédula de fecha 14 de febrero de 1661 (13) por la cual ordenaba se pagase a los Capuchinos de Melilla 200 reales cada mes, y a los del Peñón 150 reales, "para su sustento".

La iglesia de San Miguel, única de Melilla, dejaría de existir y por ello se comenzó a construir la que ahora nos ocupa en el año 1657 en la parte más alta de la ciudad en lo que los historiadores Capuchinos llaman "lugar franciscano" en continuo contacto con la naturaleza y cercano a la población para benefeciarse la Orden de la Ciudad y los ciudadanos de la Orden en cuanto al beneficio de las oraciones y sacrificios de los frailes.

Los nuevos religiosos organizaron la vida espiritual de estos Presidios y contribuyeron eficazmente a la construcción de las iglesias de Melilla y Vélez de la Gomera (14). De la vida espiritual de la ciudad hemos de dejar constancia de la erección de las cofradías en especial de la del Nazareno y Nuestra Señora de la Soledad a la que incorporaron la imagen del Cristo de la Vera Cruz por la que la población y guarnición sentían especial veneración habida cuenta del suceso ocurrido en el año 1564 cuando en un intento de hacerse con la Plaza las tropas del Sultán de Marruecos, el Alcayde Pedro Venegas de Córdoba exhibió junto a sí el santo crucifijo sobre el torreón llamado de las Beatas, manteniéndolo en este lugar hasta que el Sultán retiró toda la tropa.

Los moros fronterizos acudían a esta plaza fuerte, a la Alafía de Melilla pra el mercado en ella establecido. El gobernador Pedro Venegas de Córdoba permitió a los moros de la Serranía de la Alcahaya, sembrar en la vega, concediéndoles el 16 de noviembre de 1557 una alafia, paz o tregua con que los obligó no sólo a pagar una cantidad de trigo, cebada, miel y cera a propoción de un caíz de simiente por junta y observar varios capítulos muy favorables a la manutención y defensa de la Plaza y permiso para sus labranzas, pastos, aguas y comercio, vendiendo sus efectos en lo que hoy se 
llama plaza de Armas entre el Foso de la Cortina Real y primer Hornabeque a la que llaman alafia o tratado de la paz.

Con motivo de lo anteriormente expuesto eran muchos los moros fronterizos que acudían a Melilla, lo mismo que a Vélez de la Gomera, siendo bastantes los que pedían el bautismo en ambas ciudades según se desprende de unas actas de la Inquisición (15) y de información contenida en los Libros Sacramentales de ambas parroquias (16).

Sirva de muestra el siguiente gráfico (17):

$\begin{array}{lr}\text { Año 1661 } & 5 \text { moros } \\ \text { Año 1662 } & 14 \text { moros } \\ \text { Año } 1663 & 13 \text { moros } \\ \text { Año } 1664 & 4 \text { moros } \\ \text { Año } 1665 & 6 \text { moros } \\ \text { Año } 1666 & 4 \text { moros } \\ \text { Año } 1667 & 4 \text { moros } \\ \text { Año } 1668 & 0 \text { moros }\end{array}$

Como consecuencia de la petición de bautismos por parte de los fronterizos, y dada la extrema pobreza de los nuevos bautizados, hubo que expedir por parte del Rey nueva Real Cédula en la que con fecha de 23 de marzo de 1662 (18) ordenaba: "se dé a Fray José de Granada una provisión de 20 sacos para vestir a los moros que quieren ser Cristianos", concediendo, al citado fray José, con esa misma fecha (19) el nombramiento de Administrador del Real Hospital y Botica (20) a su favor y el de los Vicarios que le sucedieren en el cargo.

Referente a la Botica, expresamente, se ordenaba por el Rey que tuviese el referido fray José la llave de la Botica, extendiese las recetas y las rubricase, y que no se diera nada sin su aprobación y consentimiento (21).

Por Real Cédula de 1 de septiembre de 1665 ordenaba el monarca: "se dé a estos religiosos cuanto les corresponde a la llegada de los batimentos procedentes de Málaga" (22).

A partir del 17 de septiembre de 1665 en que muere don Felipe IV, gran protector y benefactor de la Orden Capuchina, van a ser muy pocos los documentos reales, pero los que aparezcan serán para poner pie en pared ante el abuso que se estaba extendiendo por los presidios, donde 
sujetos pertenecientes a distintas órdenes religiosas llegaban para cumplir penas de destierro (23).

Doña Mariana de Austria, reina gobernadora por minoría de edad de don Carlos II, decretaba por Real Cédula de 19 de agosto de 1668: "Considerando el embarazo y gasto que causan en las Plazas de Africa los religiosos a quienes destierran sus prelados por diversos delitos, he tenido por bien que los que a la presente se hallaren en ellas cumplan sus destierros y eso que de aquí en adelante no se admitan sino aquellos que voluntariamente y para servicio de Dios y con licencia mía y de sus superiores que quieran pasar a ejercitarse en las buenas obras de caridad, enseñanza y administración de los oficios divinos, sin que otros que fueren desterrados puedan ir ni ser admitidos en las dichas plazas" ... Año 1668. De pedimento de Fray José de Granada, Vicario de esta plaza, dí la presente... (24). En esta fecha los Vicarios Capuchinos eran Prefectos Apostólicos.

Debido al cargo que ejercían, hubo bastantes enfrentamientos entre los Capuchinos y las autoridades llegando incluso a hacerles pasar hambre (25) y poniendo toda clase de trabas a su ministerio. Influyeron de tal forma en ellos, que tuvieron que acudir al Rey exponiéndole lo que les estaba ocurriendo, optando por abandonar ambas ciudades. Aparte el hambre, debieron también soportar a los frailes desterrados (26) y las impertinenecias de las mujeres de vida pública que ni siquiera respetaban su condición de eclesiásticos (27).

Así pues el día 20 de noviembre de 1681 y 15 de abril de 1682 las iglesias de la Concepción y Santiago pasaron a ser atendidas por los licenciados don Bernardo Liñán, don Salvador Crespo y don Francisco Laso, todos ellos pertenecientes al clero secular (28) por orden del obispo de Málaga don Alfonso de Santo Tomás; permaneciendo la iglesia de Vélez de la Gomera sin sacerdotes hasta el día 30 de mayo de 1682. (El convento existente en el Puerto de San Miguel de la Mahámora se dejó también en el año 1681, con motivo de la pérdida de aquella ciudad española).

A pesar de todos estos contratiempos, los Capuchinos de Andalucía siguieron desplazándose a Melilla en los años 1754, 1766, 1768 y 1809 para predicar la Cuaresma. Para ello fueron seleccionados fray Antonio de San Sebastián, fray Jaime Francisco de Murcia y fray Gregorio de Cabra, pertenecientes por esa época a los conventos de Antequera, Málaga y Ubrique (29). 
Don José García y Gómez, cura párroco de la parroquial de Nuestra Señora de la Concepción en Melilla, colector de misas y notario público del Obispado de Málaga, certificaba en un interesante manuscrito al que hemos tenido acceso (30) lo más destacable que en los últimos cien años había ocurrido en la ciudad, habiéndose servido para ello del Archivo Eclesiástico de la iglesia de la Concepción. En esta ocasión, es decir el 28 de octubre de 1763, el referido párroco, perteneciente al clero secular, citaba en los diferentes hechos históricos que se habían sucedido cómo los Capuchinos y después sus sucesores habían ido anotando con minuciosidad estos relatos en los diferentes libros parroquiales.

Entre otras muchas cosas relata la inauguración de la Capilla Mayor, hecho ocurrido el día 8 de diciembre de 1682 y cuya descripción minuciosa quedó reflejada en el Libro de Defunciones de esta iglesia parroquial al folio 45 vuelto.

Obligatoriamente hemos de dejar atrás algunos siglos y adentrarnos minuciosamente en el siglo actual, para hacer referencia a la fecha de 1909 conocida por todos los melillenses, fecha de trágico recuerdo por cuanto supusieron las Campaña de Marruecos.

En esta fecha llegaban a Melilla para reinstaurar la Orden Capuchina fray Ildefonso de Cuenca (muerto en Alcolea en 1931) y fray Felipe de Coín (muerto en Melilla en el año 1967), acompañados por fray Pacífico de Ronda (muerto en Antequera el día 6 de agosto de 1936 (31).

Fray Alberto de Galaroza en su Estadística de los Hermanos Menores Capuchinos de Andalucía (32) nos relata lo siguiente con motivo de la Nueva Fundación que nos ocupa: "El establecimiento de los Religiosos en esta Residencia africana estuvo desde el principio erizado de dificultades, motivadas principalmente por la llamada Ley del Candado, vigente a la sazón". Con todo ello el obispo de Málaga, don Juan Muñoz Herrera, fundó la Residencia de Padres Capuchinos por decreto de 3 de agosto de $1912(33)$.

En el año 1918, el día 18 de octubre, el Obispado hacía entrega de la iglesia de la Concepción a la Orden Capuchina mediante documento oficial (34) en el que firmado y rubricado por el doctor don José María Jiménez, Gobernador Eclesiástico Sede Vacante, se establecía el modus vivendi para el mejor servicio de Dios y asistencia de los fieles de la Parroquia de Melilla. La cláusula primera decía: "Los RR. PP. Capuchinos 
toman a su cargo y ad nutum Episcopi la Iglesia de la Concepción y la Casa Rectoral anexa a la misma, y de ambas usarán con entera independencia".

Al día siguiente, 19 de cotubre, los religiosos una vez conocida la noticia cantaron Salve Solemne a las 6 de la tarde en la iglesia de la Concepción (35). Fray Eusebio de Rebollar no se hizo esperar y saludó a los fieles de Melilla como Superior de los Capuchinos el día 1 de noviembre de 1918 , a la vez que les ofrecía la nueva residencia en la iglesia de la Concepción (36).

Los cultos celebrados con motivo de la fiesta de la Inmaculada adquirieron gran esplendor, predicando en ellos el citado fray Eusebio. y don Miguel Acosta, antiguo párroco al que se ofreció una Canongía en la Catedral de Ceuta. Sin embargo el estamento militar celebró a la Patrona de Infantería en la nueva parroquia del Sagrado Corazón, donde predicó los cultos don Antonio Paredes, capellán de la Brigada Disciplinaria (37).

Siguiendo a fray Alberto de Galaroza en el trabajo por él coordinado en la obra Los Capuchinos en la Península Ibérica (400 años de historia) (38) podemos afirmar:

La acción social no terminaba con el emplazamiento de la fraternidad capuchina. Al contrario, comenzaba a irradiar una acción multiforme sobre la población y la comarca vecina.

De esta acción multiforme se benefició la ciudad de Melilla y muchos de los soldados españoles sintieron su acción benefactora con motivo de la Guerra de Marruecos, donde fray Emiliano de Revilla y fray Manuel de Hontoria, asistieron a los apestados y enfermos, y obtuvieron el nombramiento del Gobierno Español para el canje de prisioneros.

Durante el Desastre de Annual fueron también Capuchinos quienes se ofrecieron voluntarios para dar cristiana sepultura a los cadáveres, ya en descomposición, que ellos mismo recogían por el campo de batalla. Sus nombres fueron fray Emilio de Baeza, fray Félix de Segura y fray Juan de la Cruz de Ubeda. Todos ellos fueron recompensados con la Cruz de la Beneficiencia y la Medalla al Mérito Militar (39).

De esta forma en la que los Capuchinos participan de lleno en la vida de Melilla los encontramos en el Campo de Rostrogordo y su Fuerte 
ayudando a morir a los fusilados del año 1936. "Nadie murió en Melilla sin el consuelo de los Capuchinos" (40).

Pero habría de llegar la fecha de 1940 en cuyo año el Obispado de Málaga volvía a constituir en parroquia la iglesia de la Concepción con el mismo título que conservaba desde su fundación. Sería esta la primera parroquia que como tal aceptaron los Capuchinos españoles, porque su propia legislación se lo prohibía (41).

Entonces fue nombrado nuevo párroco fray Jacinto de Chucena, emprendiendo importantes obras de restauración y consolidación en el mes de octubre de ese mismo año, siendo encargado de las mismas el arquitecto señor Cid. Gracias a la valiente decisión de fray Jacinto fueron salvadas todas las molduras y yeserías barrocas (42). En documento del Obispado, de fecha 15 de enero de 1942 y con motivo de lo anteriormente expuesto, el obispo don Balbino Santos y Oliveira, mediante decreto reconocía:

$L a$ ratificación otorgada por sus predecesores para que la citada Orden Religiosa tenga canónicamente establecida en la Ciudad de Melilla una casa religiosa.

En virtud de las facultades otorgadas por la

Santa Sede les encargaba de nuevo el regentar la Parroquia de la Concepción, debiendo tener abiertas al público y al culto las dos iglesias enclavadas en la demarcación parroquial (43) $y$ ejercer indistintamente en cualquiera de ellas mientras la Capilla Castrense pertenezca a la Jurisdicción Ordinaria. El apartado $7^{\circ}$ dejaba muy claro que la Parroquia de la Concepción sería siempre secular.

Los Capuchinos regentaron la Capilla Castrense hasta el día 30 de marzo de 1951 en que fue entregada al Estamento Militar conforme al Inventario practicado en el mes de abril de 1933 (44). A cambio de los productos sembrados en el huerto anexo a la Capilla Castrense los religiosos recibieron en concepto de indemnización 300 pesetas (45). Esto ocurría el 21 de abril de 1956, al quedar restablecida la Jurisdicción Castrense.

La entrega de la llave del antes citado huerto fue requerida para la construcción de nuevos Pabelllones Militares, el día 26 de marzo de 1956. Este huerto que en otro tiempo sirvió como Campo de Instrucción de la Com- 
pañía de Mar, fue trabajado por fray Felipe de Coín y por fray Melchor de Santa Ana y de él se abasteció durante años la Fraternidad Capuchina.

Como colofón a este trabajo de aproximación y sin más ánimo que el de hacerles partícipes de esta riqueza documental hemos de hacer referencia expresa al más valioso de los documentos (46) que ratifica todo lo anterior, y que ya fue publicado en el año 1918 por la Revista de los Capuchinos.

Este dice así:

El Rey-Mariscal del Campo Don Luis de Velázquez y Angulo, mi Alcayde de la fuerza de Melilla, aviendose entendido que en ese Presidio se apressaron en dos vezes, setenta y cinco esclavos, hombres mujeres y niños que se vendieron, y se pasó en la forma ordinaria el quinto que toca a mi Real Hacienda, y considerando que los Religiosos Capuchinos que están en esa fuerza, se hallan muy incómodos, $y$ necesitados de vivienda para su recoximiento y an ydo trattando comprar una cassa del Pagador Don Miguel de Perea que esttá ynmediata a la Yglesia, capaz y muy apropósito, para ellos, y la han concerttado en quattro mil reales de plata, $y$ assimismo lo que necesita el Hospital de ropa y otras cosas, y aunque tengo pressente quan justo es, se os de satisfazión de lo que se os deve, de vuestro sueldo. He resuelto por consuelo y alivio de esos religiosos, $y$ sus subcesores se les compre luego dicha cassa y pague el valor en que está concertada, del dinero que ha ttocado a mi Real Hacienda desttos quinttos, y que el resto de lo que ymportaren, se remitta a disttribuzión de Don Gaspar de Aranda Cavallero, Procurador General de Armadas y Fronteras de Málaga con memoria de la ropa, diettas y medizinas de que necesitare el hospital para que se convierta en lo que fuere menester, $y$ se remita sin dilación.

Dareis orden para que lo uno y lo ottro se ejecute luego aberse (hecho) embiareis zertificación para que se tenga enttendido que ya he mandado se esté con cuidado de que se pague lo que se os deve de vuestro sueldo, y de la presente hareis se notte, en los libros de la Veeduría y Contaduría de 
ese Presidio para que conste en ello estta mi resoluzión y del paradero de mi Real Hacienda. De Madrid a 21 de noviembre de 1661. Yo el rey-Por mandato del Rey nuestro Señor, Don Blasco de Loyola (45).

La anterior disposición fue cumplida y aún hoy después de 327 años de su compra sigue en pie la Casa del Pagador don Miguel de Perea, que durante muchos años fue Conventico de Capuchinos, Casa Parroquial y finalmente y de nuevo Convento-Residencia de Menores Capuchinos.

En ella se hospedaron los Diputados Liberales de las Cortes de Cádiz (48) y en una de sus habitaciones, es decir la que da a la plazuela de la iglesia, murió el diputado Sánchez Barbero (49).

Dada la importancia de este conjunto monumental dentro del Patrimonio Histórico y Artístico de la ciudad de Melilla, y por tratarse de edificios singulares cargados de historia, arte y cultura, en el mes de julio de 1984, el señor Director Provincial de Cultura, don José Luis Fernández de la Torre intervino directamente ante el Provincial de los Capuchinos para expresarle su preocupación ante la anunciada marcha de esta Orden Religiosa de la ciudad, y el consiguiente abandono del Patrimonio Histórico Artístico depositado en ellos.

La respuesta afirmativa no se hizo esperar, interviniendo el Ministro General fray Flavio Carrero.

Gracias a este mutuo interés y a la colaboración valiosa del Ministerio de Cultura han podido ser salvadas en su totalidad la sacristía del Nazareno (siglo XVII), la de San Francisco de Asís y el Antiguo Archivo Parroquial, hoy Sala de Juntas.

Y todo esto porque la Ley de 25 de junio de 1985 al amparo de la Constitución Española, expresa en su art. 46: "Los poderes públicos garantizarán la conservación y promoverán el enriquecimiento del Patrimonio Histórico, Cultural y Artístico de los pueblos de España y de los bienes que lo integran, cualquiera que sea su régimen jurídico y titularidad".

De la valiosa documentación que contenía su archivo parroquial nos da una somera idea el insigne historiador don Gabriel de Morales en sus obras Efemérides y Curiosidades y Datos para la Historia de Melilla, don Francisco Carcaño en la novela titulada La Hija de Marte, o don 
Miguel Acosta, Vicario Eclesiástico de la ciudad y párroco de esta iglesia, erudito investigador, perteneciente a las Reales Academias que llegó a afirmar que entre sus valiosos fondos se encontraba la Historia de la Ciudad escrita día a día desde su conquista (50). Hoy día este rico legado cultural está injustamente dispersado por el Archivo Diocesano de Málaga, Archivo de los Capuchinos de Andalucía, Parroquia del Sagrado Corazón, parroquia de San Agustín (51) y en la misma sede de la Parroquia de la Purísima Concepción, donde a pesar de los pocos documentos que se conservan siguen estos mostrándonos la grandeza histórica que encierra el singular edificio.

No quisiera acabar sin aprovechar la ocasión que ustedes me brindan para reconocer públicamente la labor que desempeñan todos y cada uno de los funcionarios de la Dirección Provincial de Cultura, cuyo director provincial, don José Luis Fernández de la Torre no ha dudado ni un sólo instante para salvar el primer monumento religioso de la ciudad.

Por todo ello señoras y señores, muchas gracias por al atención que me han dispensado y por el apoyo que ustedes prestan a quienes estamos interesados en escudriñar la historia de nuestra tierra. 


\section{ALGUNAS DE LAS FBCHAS MAS IMPORTANTES}

1648

1657

1660

1661

1663

1668

1680

1682

1741

1751

1751

1751

1751

Petición al Papa para que los Capuchinos vengan a Africa.

Primera piedra de la Iglesia, dedicada después a Nuestra Señora de la Concepción.

Real Cédula de Felipe IV, enviando Capuchinos a Melilla y al Peñón de Vélez de la Gomera.

Real Cédula de Felipe IV concediendo 200 y 150 reales respectivamente.

Nombramiento de Patrono Principal a favor de San Francisco de Asís, y dedicación de la iglesia de la Concepción realizados por fray Basilio de Antequera que reunió al pueblo en forma de cabildo para realizar dicha votación.

Doña Mariana de Austria, a petición de fray José de Granada, prohibe la entrada de sacerdotes y religiosos para sufrir destierro.

El gobernador Diego Toscano de Brito viendo la iglesia que amenazaba ruina y no se podía celebrar en ella teniendo su Capilla Mayor en albarca la hizo reedificar y cubrir, añadiendo una nueva capilla para el Sagrario con bóveda y entierro muy primoroso.

Bendición de la iglesia de la Concepción y su Capilla Mayor.

Se traslada al Altar Mayor de la iglesia de la Concepción la imagen de Nuestra Señora de la Victoria, Patrona de la Ciudad.

Se sacó a la Virgen en Procesión de Rogativas y se salvaron los barcos que estaban en el puerto.

Es construido el Camarín para la imagen de la Patrona.

Se sacó a Nuestra Señora de la victoria y cesó el viento de sudeste.

Comenzó la restauración del edificio llamado Conventico. 
1752

1752

1756

1764

1774

1793

1837

1838

198

Se acabó dicha obra.

Las lluvias dañan la iglesia parroquial terminando las nuevas obras en 1757.

Ratificación de Juramento del Patronazgo de Nuestra Señora de la Victoria.

Las campanas de la iglesia parroquial que son propiedad del Rey pesan 80 arrobas.

Se traslada la Virgen de la Victoria a la Cueva del Conventico.

Vuelve la imagen de la Patrona a la iglesia parroquial. Un cañonazo daña la iglesia parroquial durante la celebración de la Misa Mayor.

El Canónigo don Gregorio Alvarez mantuvo la Plaza dentro de la Soberanía Nacional para el rey Fernando VII.

Solemne Te Deum de acción de gracias y Juramento a Carlos V como rey.

Visita la iglesia parroquial el rey Alfonso XIII.

Visitó la iglesia la princesa Beatriz de Sajonia, esposa de su alteza el infante don Alfonso de Orleáns.

El arzobispo de Tarragona imparte el Sacramento de la Confirmación, por primera vez, en la iglesia parroquial.

Es despojada esta iglesia de su Monumental Archivo, siendo trasladado el mismo junto a otros objetos de valor, imágenes, relicarios, Lignum Crucis, bancos, reposteros y colgaduras, armonium, etc., ante el asombro de los vecinos del pueblo, a la nueva iglesia del Sagrado Corazón de Jesús. (Hoy en parte en el Obispado de Málaga).

A petición del Superior de los Capuchinos se ejecuta el Nuevo Retablo para la Capilla Mayor (fray Jesús de Pedro Abad).

El acorazado Jaime I bombardea la iglesia de la Concepción. Tan sólo logra romper los cristales de los ventanales de la nave central. 
El Obispado de Málaga la erige en parroquia con el título de Purísima Concepción.

1940 El Vicario Rector fray Jacinto de Chucena es nombrado por el obispo de Málaga encargado de la iglesia parroquial de Nuestra Señora de la Peña en la isla de Alhucemas.

1948 (52) Coronación canónica de la Patrona de la ciudad, Nuestra Señora de la Victoria. A propuesta y petición del Superior de los Capuchinos, fray Luis de Ausejo (Medalla de Oro de la Ciudad).

1954 Con motivo de la celebración del Año Santo Mariano la imagen de Nuestra Señora de la Victoria fue instalada en la plaza de España junto a Nuestra Señora del Rosario.

1971 Los príncipes de España don Juan Carlos y doña Sofía visitan la iglesia de la Concepción, besando la imagen de la Patrona.

1987 El Ministerio de Cultura salva de la ruina la Sala y

1991 El Ministerio de Cultura comienza la primera fase de restauración de todas las cubiertas de la iglesia parroquial.

Martes Santo La imagen de Nuestra Señora de la Victoria es trasladada desde la iglesia parroquial a la Sala de Juntas de la Asociación de Estudios Melillenses donde queda instalada de forma provisional la parroquia de la Purísima Concepción, celebrándose en ella los cultos de dicha parroquia.

Se da la circunstancia histórica de que la Patrona no salía de la iglesia parroquial desde el Sitio de $\mathbf{1 7 7 4}$ en que fue trasladada a la Cueva del Conventico. El Ministro General de los Capuchinos fray Flavio Roberto Carrero, llega a Melilla procedente de Roma. Visita a Nuestra Señora de la Victoria y ante ella celebra la Eucaristía. Le acompaña en el acto el Pro- 
vincial de los Capuchinos y el Secretario para el habla hispana.

1991

Segunda fase del Proyecto de Restauración de las cubiertas e interiores y fachadas de la iglesia parroquial por un valor de 78.498 .431 pesetas.

Durante estos tres largos siglos, ha sido visitada por reyes, príncipes, jefes de estado, por el Nuncio del Papa, cardenal Tedeschini, diversos arzobispos, obispos y prelados, representantes consulares de diversas naciones, y un largo etc. de autoridades civiles y militares.

Bajo sus bóvedas descansan los restos de más de mil héroes y de defensores de la ciudad, alcaydes, veedores y gobernadores.

De sus muros y altares penden las armas de la Casa de Austria, Medina Sidonia y Reino de España. Asimismo la heráldica del papa Alejandro VII, y las propias de la Orden Franciscano-Capuchina, viéndolo así el poeta

\section{EL ESCUDO FRANCISCANO}

Este divino blasón

$y$ sacrosantas señales

advierta el mundo que son

armas de esta religión,

aunque son armas reales.

Porque el Rey que las ganó

$y$ pudo disponer de ellas,

sólo a Francisco las dio

y el por honrarse con ellas,

a sus hijos las dejó.

Anónimo del siglo XVII

Por todo ello comenzamos nuestra investigación. 


\section{RELACION DE PERSONAS ILUSTREB ETTERRADAS}

BN BL MAUSOLRO DE IA IGLESIA DE LA CONCPECION

3-X-1674 Don Diego de Arce, Alcayde.

5-X-1687 Don Francisco López Moreno, Gobernador.

I-XI-1715 Don Patricio Gómez de la Hoz, Gobernador.

I-VIII-1719 Don Francisco Ibáñez Rubalcava y Velasco, Gobernador.

3-VI-1725 Don Francisco de Alba Vallejo, Gobernador.

8-X-1730 Don Alonso de Guevara y Vasconcellos, Gobernador.

11-III-1732 Don Juan Andrés del Thoso, Gobernador.

22-IV-1757 Don Antonio de Villalba y Angulo, Gobernador.

27-I-1772 Don Miguel Fernández Saavedra, Gobernador.

3-VII-1779 Don Miguel Zazo Camacho.

17-II-1821 Don Jacinto Díaz Capilla, Gobernador.

1888 Don Juan Villalonga Soler, Gobernador.
7-I-1672 Fray Martín de Somalvide, O. H. Médico de la Plaza, muerto al hundirse una casa a causa de la lluvia.
31-V-1680 Fray Francisco de Villaverde, O. H. Médico, murió de peste.
9-X-1695 Fray Martín de la Escalera, O. H. Cirujano de la Plaza.

Asimismo se va a comenzar a realizar gestiones para el traslado de los Religiosos Capuchinos enterrados en el Cementerio Municipal de Melilla a la iglesia de su convento.

Padre Cristóbal de Ubeda, Misionero Capuchino.

Padre Pío de Sanlúcar de Barrrameda, Misionero Capuchino.

Hermano fray Felipe de Coín, Limosnero.

Franciscano de la Provincia de Nador.

Padre Ramón López Capelán, sacerdote párroco de Santiago de Nador. 
1. Autos para la Ratificación del Patronazgo de Nuestra Señora de la Victoria, Patrona de Melilla, año 1756. Melilla, sin paginar, Archivo Provincial de los Capuchinos de Andalucia. Sevilla. Copia del manuscrito original.

2. Carta, año 1934. Melilla, Archivo antes citado.

3. Provincia religiosa fundada por el papa Urbano VIII mediante el breve "cum sit nobis" del 11 de agosto de 1637.

4. Documento publicado por fray Ambrosio de Valenciana, Reseña Histórica de la Provincia Capuchina de Andalucia, 5 vols. Sevilla, Imp. de la Divina Pastora, 1906-1908.

\section{Ibidem.}

6. Fue el primero en pisar tierra melillense, siendo elegido Ministro Provincial en el año 1665 en el Capítulo Provincial celebrado en Granada. Murió en el convento de Cádiz en 1675.

7. De este personaje se conservan sus actuaciones como Comisario de la Inquisición en el fuerte de Vélez de la Gomera. Mantuvo amplia correspondencia y señalados favores de Felipe IV y Carlos II.

8. Publicado en Reseña Histórica..., op. cit.

9. Consecuencia del Patronato Regio por el que los Reyes enviaban a los religiosos y sacerdotes.

10. Comenzada a levantar en tiempos de fray Juan de Vera, Mercedario, y acabada en tiempos de los Capuchinos. Su fachada original sigue las Normas que las Constituciones Capuchinas asignaban a este tipo de construcciones.

11. Documento original en Archivo Provincial de los Capuchinos de Andalucía, Sevilla.

12. Real Cédula en Arch. Prov. Cap. And. Sevilla.

13. Real Cédula en Arch. Prov. Cap. And. Sevilla.

14. Ambas iglesias siguen la tradición Capuchina en su estilo peculiar y decoración Sevilla.

15. Documentos en Arch. Prov. Cap. And.

16. Depositados en el Obispado de Málaga, excepto los pertenecientes a los últimos cien años que se encuentran en la actualidad en la parroquia del Sagrado Corazón de Melilla. Sólo a partir del año 1940 los conserva la de Concepción de Melilla.

17. Gráfico publicado en 1918 por la Revista religiosa $\mathrm{El}$ Adalid Seráfico, año 1918.
Sevilla, Imp. de la Divina Pastora. Sección "Cartas de Melilla”, H. de Lázaro.

18. Arch. Prov. Cap. de And. Sevilla.

19. Interesante documento que aclara las afirmaciones gratuitas vertidas por el profesor Salafranca, Bosquejo Histórico de la Población y Guarnición de Melilla (1497-1874). Granada, Copistería La Gioconda, 1987, pág. 109, notas 89, 92 y 94. La Real Cédula de 23 de marzo de 1662 dice textualmente: "... Sobre que los bienes, y de lo que quedase debiendo a los soldados, y presidiarios que mueren en esa Plaza se hiciese bien por sus almas; considerando el Consejo que es justo que esto se ejecute $Y$ los ahorros de vino, se conviertan en lo que dejaren declarado por su última voluntad, deviendo ser esto bajo instrumento que lo justifique, y las misas que se les hubieren de decir se libre la limosna de aquellos ahorros, pero ha de ser a la obligación de Vuestra Merced, el dar cuenta ante su Prelado de haberse cumplido, o mandar decir las misas correspondientes al producto de la que perciviese y así mismo que si muriese alguno o algunos $\mathrm{Ab}$-intestato se les apliquen las misas que les tocaren de sus bienes, y bastimentos que se les quedaren deviendo..." . Más tarde esta sería de nuevo ratificada en iguales términos el día 17 de marzo de 1716. Original inédito. Archivo Provincial Capuchinos de Andalucía. Sevilla.

20. Arch. Prov. Cap. de And. Sevilla.

21. En contraposición de las autoridades que ponian Mayordomo sin su autorización $y$ consentimiento cuando el ponerlo era prerrogativa de los Vicarios.

22. Hubo de intervenir el Rey, porque no se les hacía entrega de los bastimentos que les correspondian. Arch. Prov. Cap. de And. Sevilla.

23. Pertenecientes a los Mercedarios, Agustinos, Carmelitas y Hermanos de San Juan de Dios. Arch. Prov. Cap. de And. Sevilla.

24. Archivo antes citado

25. Idem.

26. Reseña Histórica de la Provincia Capuchina de Andalucía. Sevilla, Imp. de la Divina Pastora, 1906-1908.

27. Real Cédula en Arch. Prov. Cap. de And. Sevilla. En ella concedía el monarca Una Ración de Trigo a las mujeres de vida pública, "aún cuando se conviertan de su mal, y se casen". Estas y los soldados trataban a los religiosos de forma irreverente. 28 de abril de 1674 . 
28. Reseña Histórica..., antes citada.

29. H. de Lázaro, "Cartas de Melilla", $E l$ Adalid Seráfico, año 1918. Sevilla.

30. José García Gómez, Noticias sacadas del archivo eclesiástico de la ciudad de Melilla. Melilla, año 1763, Archivo Histórico Militar de España, Madrid.

31. Fray Alberto González Caballero, Estadistica de los Hermanos Menores Capuchinos de la Provincia de Andalucía, año 1977. Sevilla, Talleres Tipográficos El Adalid Serúfico.

32. Arch. Prov. Cap. de And. Sevilla.

33. Idem.

34. Idem.

35. El Telegrama de El Rif, año 1918. Melilla, Dirección Provincial del Ministerio de Cultura, Melilla.

36. Idem.

37. Idem.

38. Fray Alberto González Caballero, Los Capuchinos de la Península Ibérica. Sevilla, Talleres Tipográficos El Adalid Seráfico, año 1985.

39. Documento inédito, Archivo Convento de Capuchinos de Melilla.

40. Citado por fray Alberto González Caballero, en obra anteriormente citada.

41. Idem. Melilla.

42. Archivo Convento de Capuchinos de

43. Idem.

44. Idem.

45. Idem.

46. Original en Archivo Diocesano de Málaga, publicado por $\mathbf{H}$. de Lázaro, "Cartas de Melilla", El Adalid Seráfico, año 1918. Sevilla.

47. Idem.

48. Calatrava, Ramajo y Sánchez Barbero, en 30 de junio de 1816. Aparte sufrieron prisión en el Fuerte de Victoria Grande.

49. Precisamente el hecho ocurrió el día 24 de octubre de 1819.
50. Los fondos documentales fueron transportados en sacos a lomos de borriquillos morunos, según el testimonio de antiguos vecinos del pueblo, que contemplaron horrorizados cómo volaban por el Túnel de Florentina los valiosos documentos que sobresalian por las bocas de los sacos.

51. En el archivo de esta parroquia se encuentran depositados unos 500 documentos y Litoros Sacramentales todo ello de la parroquia de Santiago El Real de Vélez de la Gomera.

52. Como nota curiosa y a modo de información sirvan como ejemplo las siguientes cifras:

La corona de Nuestra Señora de la Victoria, fabricada en los Talleres del señor don José Madrid, de la capital de España, contiene las siguientes piedras preciosas: 586 brillantes blancos de primera calidad. 184 zafiros. 217 rubies. 15 chapas de esmalte fino.

El Escudo de la ciudad de Melilla, en esmalte, oro y platino.

Por su parte la del Niño Jesús que soporta sobre su brazo la Patrona, contiene las siguientes joyas: 372 rosas holandesas. 132 zafiros. 203 rubies.

Ambas fueron adquiridas con el producto de los donativos en metálico, aportación de oro y joyas que efectuaron generosamente los melillenses.

Ambas son de Estilo Imperial, de ocho florones cada una de ellas, de oro en su totalidad, y montadas las piedras preciosas sobre platino.

Todo esto, unido al valor sentimental, ha dado lugar a que por motivos de seguridad se encuentre depositada en la sucursal del Banco Central de Melilla.

Ostenta la propiedad de esta preciada joya la Congregación de Nuestra Señora de la Victoria, Patrona de Melilla.

Un total de 1.694 piedras preciosas producto de la devoción de los melillenses hacia la Madre de Dios. 
Archivo de la parroquia de San Agustín, Melilla.

Archivo de la Provincia Capuchina de Andalucía, Capuchinos de Sevilla.

Archivo de la Fraternidad de Capuchinos, Melilla.

Archivo de Nuestra Señora de la Concepción, Melilla.

BLASCO LOPEZ, José Luis: “Aportación documental para un profundo estudio del conjunto monumental formado por la Real Iglesia de la Concepción y Conventico de Capuchinos", Rev. Publicaciones de la Escuela de Magisterio, de Melilla. Universidad de Granada, $1989, n^{\circ} 16$.

Boletín Oficial del Obispado de Málaga, años 1912, 1918 y 1940.

CARCAÑO MAS, Francisco: La Hija de Marte. Melilla, Excmo. Ayuntamiento, 1988.

FERNANDEZ DE CASTRO Y PEDRERA,

Rafael: "Las ermitas de la Virgen de la Victoria excelsa Patrona de Melilla", en El Telegrama
GONZALEZ GABALLERO, fray Alberto: Estadistica de los Hermanos Capuchinos de Andalucía. Sevilla, Talleres Tipográficos El Adalid Seráfico, 1977.

GONZALEZ CABALLERO, fray Alberio: Los Capuchinos en la Península Ibérica. SeviIla, Talleres Tipográficos El Adalid Seráfico, 1985.

IRIARTE DE AZPURZ, fray Lázaro: Historia Franciscana. Valencia, Editorial Asís, 1979.

MIR BERLANGA, Francisco: Floresta de pequeñas historias. Granada, Copargraf, 1983.

MORALES MENDICUTIA, Gabriel: Datos para la historia de Melilla. Melilla, Tip., El Telegrama del Rif, 1909.

MORALES MENDICUTIA, Gabriel: Efémerides y curiosidades. Melilla, Tip., El Telegrama del Rif, 1918.

VALENCINA, fray Ambrosio de: Reseña Histórica de la Provincia Capuchina de Andalacía, 5 vols. Sevilla, Imprenta de la Divina Pasıra, años 1906-1908. 